\title{
Student's Prevailing, Confidence, and Drives: LIWC Analysis on Self-Description Text
}

\author{
$1^{\text {st }}$ TA Syah \\ Faculty of Psychology \\ Universitas Muhammadiyah Lampung \\ Lampung, Indonesia \\ tansri.adzlan@gmail.com
}

\author{
$2^{\text {nd }} S$ Apriyanto \\ Faculty of Applied Science and \\ Technology \\ Universiti Tun Hussein Onn Malaysia \\ Malaysia
}

\author{
$3^{\text {rd }}$ A Nurhayaty \\ Faculty of Psychology \\ Universitas Muhammadiyah Lampung \\ Lampung, Indonesia
}

\begin{abstract}
Using a sample of 26 participants, we asked the students to prepare a text in written self-description at the end of the final path presentation in the sixth semester. One interesting thing is the relationship between personality differences and the types of words that people use. Recent studies covers an observing the relationship between personal qualities and the use of language in creating selfdescription. Text files are organized for transcription LIWC analysis to calculate the percentage of clout, authentic, and drives that student's use. The results supported this possibility: LIWC's clout, authentic, and drives dictionaries can be used as indicators of the student's prevailing, confidence, motives and needs, we found that when calculated on written text, LIWC scores were connected with language dimension and psychology issues. These findings recommend that LIWC clout, authentic, motives, and needs dictionaries possibly will catch self-reported subjective emotion experience when applied to everyday activities. To enrich students' confidence, power, motives, and needs toward the psychology issues faced by the students, students should be stimulated to discover the field of psychological processes and linguistic patterns by detecting their emotional and perceptual experiences.
\end{abstract}

Keywords-Prevailing, Confidence, LIWC

\section{INTRODUCTION}

Although the idea that language and personality do not matter, researchers have just begun to systematically study how the use of words is associated with personality differences [1] [2]. The latest results show that natural language patterns reveal the psychological characteristics of people [3]. Stand out with still very personal, which makes the optimal optional for exploring the distinctions of the individual [4][5]. The difference of language has become a key factor in social and personality psychology. On the other hand, there is an insignificant relationship between personality traits and language use [5]. There is not enough influence on the length of the original writing to be able to observe a person's personal effects.

Writing form that is close to the person is the scope of self-development. There is now a lot of research devoted to the expression of individuals in a broader language area [6]. This study is based on the idea that personality is structured in terms of personal storytelling. And culture, most of which are language mediators [7]. It is reasonable to assume that the use of speech patterns in speeches can reveal a stronger relationship with personality characteristics than those found by using the current consciousness or essay writing practice. Because personal storytelling is important to themselves, their content and style should reflect personality differences in various ways [8].

\subsection{Language Dimension}

Clout - Clout refers to the term of self-confidence. That's why many people are trying to find it. On the other hand, you can convince the person who speaks clearly to stand up. His head answers the question with confidence and is ready to accept when he doesn't know anything.

Authentic - In positive psychology, planning about the importance of quality of life becomes interesting to be well prepared [9] [10]. Nowadays, in general psychology of counselling, the most basic and important aspect of well-being is accuracy and not just as a prerequisite for well-being [10]. It is believed that promoting legitimacy can improve well-being because it helps people to have clear and consistent feelings of self that lead to their goals [11][12].

Drives - When someone tells the same story, they will not necessarily use the same method. Different words can affect different interpretations of a story. The use of the right words can maximally explore more in a story. This is a window into the world of storytelling [13]. The overall dimension is a combination of Achievement, Affiliation, Power, Reward, and Risk [14].

\section{METHOD}

\section{A. Participants}

Participants consisted of 26 undergraduate students from the Universitas Muhammadiyah Lampung (15 females and 9 male), with an age range of 21-22 years. Students come from the third-year undergraduate psychology classes.

\section{B. Materials \\ 1) Writing assignment}

Participants were asked to write their descriptions. This process was facilitated by a self-study that guides participants through the writing process. Participants were asked to indicate three things in their lives; People, things or places. 
2) Linguistic Measures by Linguistic Inquiry and Word Count (LIWC)

LIWC is a widely used tool that defines common English words as one of 68 different categories. (Such as

\section{RESULT}

A. Language Extraction from LIWC

In a view of psychological perspective proves that function language usage reflects and is a dependable marker of personality and a variety of mental processes, cognitive thinking styles and psychological states [16]. pronouns, adverbs, work-related words, religious words, etc.) [8] [15]. This software accepts frequencies for many words, sorted by type, psychology, and language.

Self-description of students at Universitas Muhammadiyah Lampung, Indonesia was the data for this study.

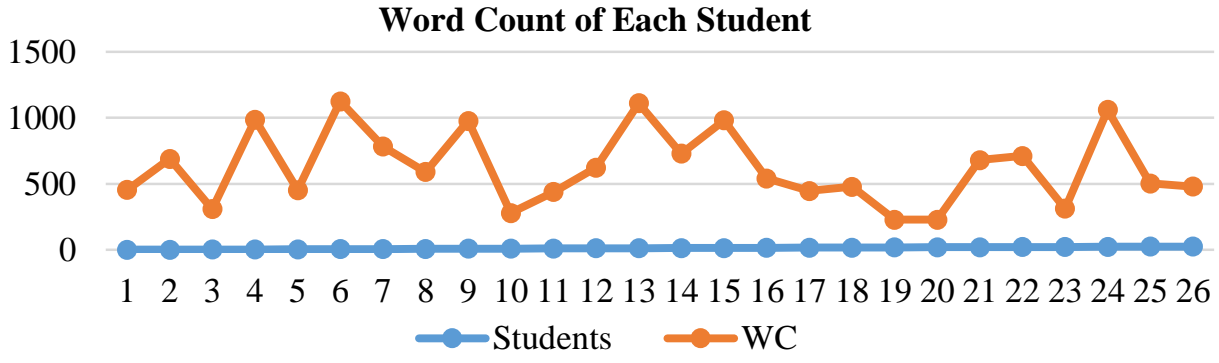

Figure 1. Words Count Data of Each Student

Figure 1 shows the number of words most frequently displayed in the student's self-description. Source test was first calculated and processed, and the extracted text was compiled without punctuation, numbering, common words, etc. The main focus is on three main functions (Algorithmic Language); Clout, Authentic, and Drives to indicate which language students are using. Since the example of this paper was taken from the first language source (Indonesia), it is important to consider in advance whether they have language features or not, encoding, deletion, etc. It was performed for initial data processing.

\section{Drives- Language Dimension}

Affiliation Achieve $\times$ Power

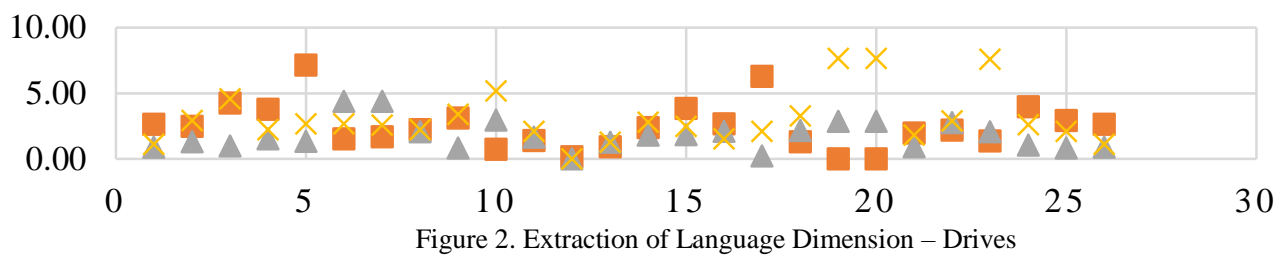

Motives and Needs

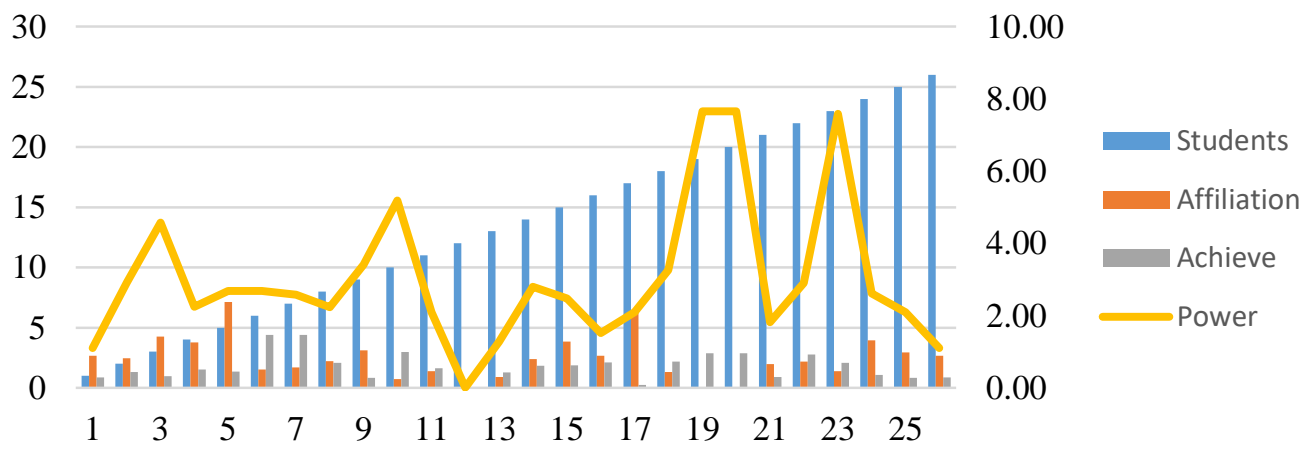

Figure 3. Motives and Needs Features of Drives

Layers of the students told in reaction could arrange for main clues to their requirements for affiliation, power, and achievement [16]. Students who discovered the affiliation to others looks to have positive social communication; student's achievement revealed the orientations to success and failure or achievement struggling. A high number is associated with positive 
success; students who mentioned higher numbers of power are associated with control in social grading.

Authentic - Language Dimension

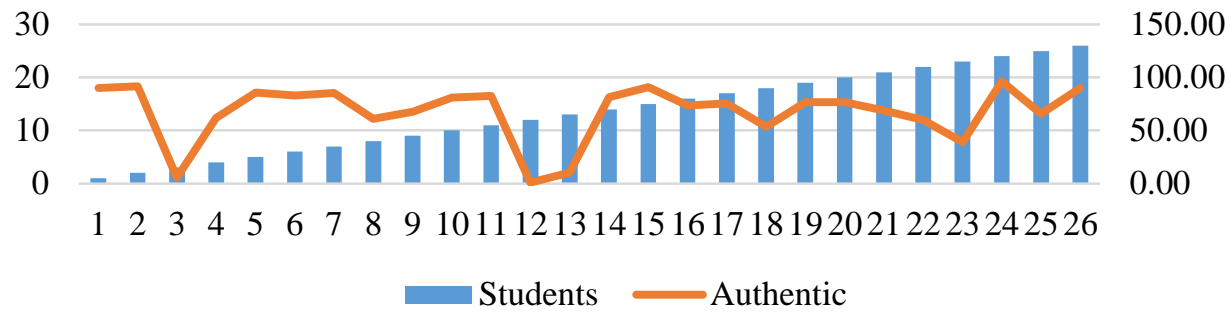

Figure 4. Extraction of Language Dimension - Authentic

Figure 4 shows the language abbreviations in authentic dimension. The correctness or knowledge of someone's beliefs and feelings and following them is the same as 'being yourself' [17]. The concept of validity is to think about building between self-knowledge and self- control of behaviour. From this perspective, knowledge of the best things can significantly impact people's lives because it helps them to create good lives as an archer with the goal of trying [9].

\section{Clout - Language Dimension}

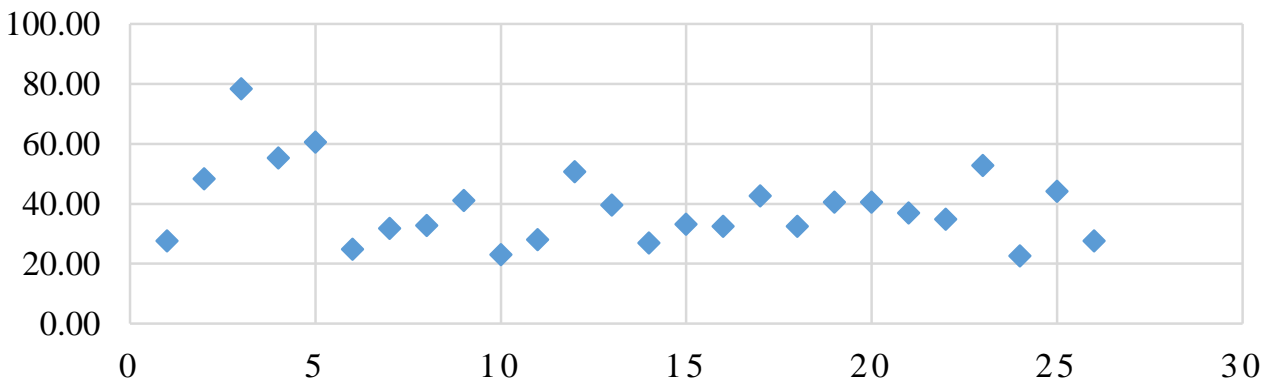

Figure 5. Extraction of Language Dimension - Clout

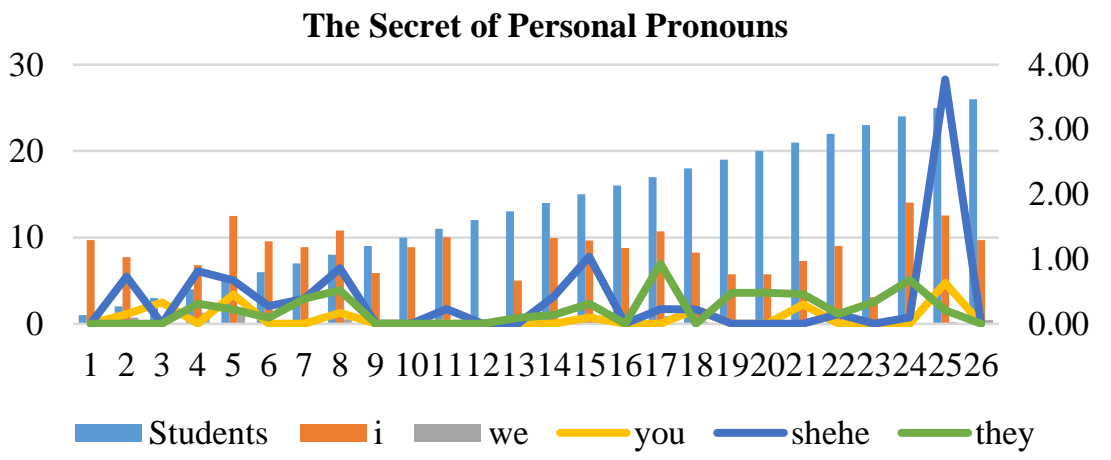

Figure 6. Personal Pronouns Features of Clout

Figure 6 shows that the use of "I" are the percentage of the pronouns used (I, me, my) and we, you, she, he, them. Clout can be felt when using the pronouns of people

\section{DISCUSSION}

\section{A. Clout}

LIWC was applied to analysed each transcript [18]. LIWC uses more than 2,300-word counting strategies or keywords in each text file. The only use of the first person shows that he/she expresses his thoughts and feelings. and the number of words. This self-reference is an indication that people are involved in responding to the mission of self-explanation and passion.

Using third-person pronouns refers to others who are publicly known [19]. Pennebaker was disrupted by views and personal concerns. Even on important topics during a police investigation, He expects his answers to have phrases like "I think" or "I'm worried". Earlier in his running, he said these words "we" or "you" than "I". During this time, a phenomenon that often occurs when 
people feel depressed and lonely, socially, or emotionally [20][21].

\section{B. Authenticity}

The biggest achievement is being yourself in a world that is trying to keep you as something else. Being yourself will lead to better results than trying to be a person or something else. The authenticity or knowledge of their thoughts and feelings and their actions are synonymous with you [17].

Psychosis and suffering are caused by a lack of authenticity and it will make a person unnatural, frustrated and unappreciated [22]. Someone needs to have authenticity because it has a positive impact and capable of directing others to get a better life and full of confidence and surely be consistent with the purpose of life [12]. Openness to accept, respond, and think openly about an emotional reaction then it called by an authentic person. When doing something without limiting oneself and identity in daily life, that is the definition of authenticity [9] and claims that it has four components: awareness, dispassionate processing, behaviour, and relational orientation.

\section{Drives}

They are Achievement, Power, Reward, and Risk [5]. The study of linguistics and psychology is considered necessary to study these dimensions. The word counting strategy is based on the theory that people use to convey psychological content that goes beyond an accurate and independent understanding of their semantic structure [23]. Achievement is an ability for relishing the mastery of interesting tasks. Affiliation is a capability for appreciating close, pleasant interactions and connect with friend, lover, soul mate, beloved [24]. Power is an aptitude for relishing one's impression on others. For power, the students would be involved in learning to accomplish hypnosis [5]. Example, the result shows that $0.23 \%$ student's deficiency of power in the social. Speakers use it to avoid coercion and give the speaking partner the choice. Speakers can avoid the impression of coercion by emphasizing the interests of others by using apologies, or by asking questions that give the possibility to answer "No" [3], [4], [13], [23], [25].

\section{CONCLUSION}

It seems that personality traits are clearly related and effective in using words through self-explanations. Writing exercises include a lot for yourself, as well as personal statements that arise, creating important characteristics of a person's personality [26][8]. While LIWC analysis has verified very worthwhile for groping several psychological spectacles [3], [13], [23], [27], and is exceptional in its systematic methodology, it silently only observes the use of words. Analytical methods that consider a higher semantic structure would be clear if they were created.

While positive participation can be restructured into elements that maintain accuracy and uniqueness and can create new positive engagement and inspire people to receive the identity of others. This participation can help people realize their true self through self-reflection, motivate them to manage their true self in their responses and provide a positive solution to reveal their uniqueness that does not affect demand. To maintain authenticity, we must first understand that our presence in human situations is often surrounded by cultural boundaries. The results of this study show that patterns in the form of strong content coding tests can be evaluated through prejudiced rectilinear arrangements of the LIWC category that has a great convergence from power, achievement, and affiliation.

\section{ACKNOWLEDGMENT}

The authors gratefully acknowledge the financial support from Universitas Muhammadiyah Lampung, and we would like to thank the anonymous reviewers for their comment on this article.

\section{REFERENCES}

[1] L. A. Fast and D. C. Funder, "Personality as Manifest in Word Use: Correlations With Self-Report, Acquaintance Report, and Behavior," J. Pers. Soc. Psychol., vol. 94, no. 2, pp. 334-346, 2008.

[2] M. R. Mehl, S. D. Gosling, and J. W. Pennebaker, "Personality in its natural habitat: Manifestations and implicit folk theories of personality in daily life," J. Pers. Soc. Psychol., vol. 90, no. 5, pp. 862-877, 2006.

[3] J. Pennebaker, M. R.Mehl, and K. G. Niederhoffer, "Psychological Aspects of Natural Language Use: Our Words, Our Selves," Annu. Rev. Psychol., vol. 54, pp. 547-577, 2003.

[4] M. R. Mehl and J. W. Pennebaker, "The Social Dynamics of a Cultural Upheaval: Social Interactions Surrounding September 11, 2001," Psychol. Sci., vol. 14, no. 6, pp. 579-585, 2003.

[5] J. W. Pennebaker and L. A. King, "Linguistic styles: Language use as an individual difference," J. Pers. Soc. Psychol., vol. 77, no. 6, pp. 1296-1312, 1999.

[6] J. B. Hirsh and J. B. Peterson, "Personality and language use in self-narratives,” J. Res. Pers., vol. 43, no. 3, pp. 524-527, 2009.

[7] J. Bruner, "The Narrative Construction of Reality," Crit. Inq., vol. 18, no. Autumn 1991, 1991.

[8] K. C. McLean, M. Pasupathi, and J. L. Pals, "Selves creating stories creating Selves: A process model of self-development," Personal. Soc. Psychol. Rev., vol. 11, no. 3, pp. 262-278, 2007.

[9] M. H. Kernis and B. M. Goldman, "A Multicomponen Conceptualization of Authenticity: Theory and Research," $A d v$. Exp. Soc. Psychol., vol. 38, no. 06, pp. 283-357, 2006.

[10] A. M. Wood, P. A. Linley, J. Maltby, M. Baliousis, and S. Joseph, "The Authentic Personality: A Theoretical and Empirical Conceptualization and the Development of the Authenticity Scale," J. Couns. Psychol., vol. 55, no. 3, pp. 385-399, 2008.

[11] C. R. Rogers, On Becoming a Person. Boston: Houghton Mifflin Company, 1961

[12] W. A. Reich, E. M. Kessel, and F. J. Bernieri, "Life Satisfaction and the Self: Structure, Content, and Function," J. Happiness Stud., vol. 14, no. 1, pp. 293-308, 2013.

[13] J. W. Pennebaker and L. D. Stone, "Words of Wisdom : Language Use Over the Life Span," Personal. Soc. Psychol., vol. 85, no. 2, pp. 291-301, 2003.

[14] C. K. Chung and J. W. Pennebaker, "Linguistic Inquiry and Word Count (LIWC)," Appl. Nat. Lang. Process., no. 2015, pp. 206229, 2015.

[15] R. B. Slatcher, C. K. Chung, J. W. Pennebaker, and L. D. Stone, "Winning words: Individual differences in linguistic style among U.S. presidential and vice presidential candidates," J. Res. Pers., vol. 41, no. 1, pp. 63-75, 2007.

[16] Y. R. Tausczik and J. W. Pennebaker, "The psychological meaning of words: LIWC and computerized text analysis methods," J. Lang. Soc. Psychol., vol. 29, no. 1, pp. 24-54, 2010. 
[17] A. Mengers, "The Benefits of Being Yourself: An Examination of Authenticity, Uniqueness, and Well-Being," pp. 1-76, 2014.

[18] J. W. Pennebaker and M. E. F. \& R. J. Booth, "Linguistic Inquiry and Word Count (LIWC)," Appl. Nat. Lang. Process., no. April, pp. 2-8, 2016.

[19] J. W. Pennebaker and T. C. Lay, "Language Use and Personality during Crises: Analyses of Mayor Rudolph Giuliani's Press Conferences," J. Res. Pers., vol. 36, pp. 271-282, 2002.

[20] J. W. Pennebaker and A. Graybeal, "Patterns of natural language use: Disclosure, personality, and social integration," Curr. Dir. Psychol. Sci., vol. 10, no. 3, pp. 90-93, 2001.

[21] S. S. Rude, E. M. Gortner, and J. W. Pennebaker, "Language use of depressed and depression-vulnerable college students," Cogn. Emot., vol. 18, no. 8, pp. 1121-1133, 2004.

[22] M. R. Leary, "Interpersonal aspects of optimal self-esteem and the authentic self," Psychol. Inq., vol. 14, no. 1, pp. 52-54, 2003.

[23] M. L. Newman, J. W. Pennebaker, D. S. Berry, and J. M. Richards, "Lying Words: Predicting Deception From Linguistic Styles," Soc. Personal. Soc. Psychol. Inc., vol. 29, no. 5, pp. 665675, 2003.

[24] O. C. Schultheiss, R. A. Sherman, and F. Atlantic, "Are implicit motives revealed in mere words? Testing the marker-word hypothesis with computer-based text analysis," vol. 4, no. October, pp. 1-20, 2013.

[25] M. R. Mehl and J. W. Pennebaker, "The Sounds of Social Life: A Psychometric Analysis of Students' Daily Social Environments and Natural Conversations," J. Pers. Soc. Psychol., vol. 84, no. 4, pp. $857-870,2003$

[26] D. P. McAdams, "The Psychology of Life Stories," Rev. Gen. Psychol., vol. 5, no. 2, pp. 100-122, 2001.

[27] M. R. M. JamesW. Pennebaker and and K. G. Niederhoffer, "Learning a Natural Language Interface with Neural Programmer," Psychology, 2003. 